\title{
Research Cage Wind Turbines' Dynamic Characteristics Based on Time-varying Parameters
}

\author{
Gu Bo ${ }^{1,2}$, Liu Yongqian ${ }^{1}$, Xu Qiang ${ }^{1}$ and Kang Shun ${ }^{1}$ \\ ${ }^{1}$ State Key Laboratory of Alternate Electrical Power System with Renewable Energy \\ Sources (North China Electric Power University), Beijing, 102206, China; \\ ${ }^{2}$ School of electric power, North China University of Water Resources and Electric \\ Power, Zhengzhou 450011, china. \\ gb1982@ncwu.edu.cn
}

\begin{abstract}
According to the characteristics of cage wind turbines' dynamic characteristics which change following the wind speed changes, the dynamic mathematical models of cage wind turbines major subsystems have been established, including the aerodynamic subsystem model, drive train subsystem model and generator subsystem model. Then these nonlinear dynamic models with time-varying parameters have been integrated and linearized to obtain the whole linear time-varying parameters dynamic mathematical model. To take the $2 M W$ cage wind turbines wind turbine as example, the proposed model is validated by the study on the dynamic characteristics of cage wind turbines with wind speed variation, and the results show that the proposed model could provide a theoretical support for optimal control of the cage wind turbines.
\end{abstract}

Keywords: cage wind turbines; time-varying parameters; dynamic characteristics; mathematical model

\section{Introduction}

With the advancement of science and technology as well as the growth of industrial production, people's demand for energy is also increasing. However, the reserves of conventional energy such as coal, oil and natural gas and other non-renewable energy has been declining, so it is urgent to find new renewable energy to replace the nonrenewable energy sources. As a new promising renewable source, wind energy has the advantage of clean, large storage capacity and easy development, and has been widely explored and utilized. Among various energy shares, the proportion of wind power generation has been increasing. But wind power generation also has shortcomings. The most significant one is the wind speed's variability and uncontrollability. The output power of wind turbines has cubic relationship with the wind speed. The fluctuations of wind speed bring about great difficulties to the control of wind turbine and the stable operation of the power system. In order to optimize the wind turbine control and to maintain the stability of the power system operation, it is significant to study the wind turbines' dynamic characteristics with the wind speed variation.

At present, domestic and foreign experts have been studying the dynamic performance of wind turbine. A simplified 3-order dynamic model of wind turbines was established which takes the biaxial component of rotor excitation voltage and the input mechanical torque as 
control variables, and the response characteristics of each physical variables between simplified 3-order dynamic model and precise model were compared [1-2]. The dynamic mathematical model of wind turbines in the d-q coordinate system was establish in [3], and the resistance effect was studied in the case that wind turbine is operating in variable wind speed. A simplified dynamic model of wind turbine was established, the wind turbines' dynamic process and response process under the fault of power system were researched in [45]. A large-scale dynamic model of wind turbines was established, and the dynamic response process of wind turbines under wind speed mutation was studied in [6-12]. The dynamic characteristics of tower in wind turbines operation process was researched, and the tower's dynamic characteristics under the time-varying load were given in [13-19]. The above scholars have studied the dynamic characteristics of wind turbines from different angles. The corresponding models of wind turbines were established according to their own research results, and simulation analyses were carried out, made a lot of research results. But the variability of the whole state equation of wind turbines has not been considered in above researches as well as the dynamic responses process of each component with the wind speed variation during wind turbines in the operation.

To solve the above problems, the dynamic mathematical models of cage wind turbines major subsystems have been established, including the aerodynamic subsystem model, drive train subsystem model and generator subsystem model. And then the nonlinear dynamic submodels with time-varying parameters have been integrated and linearized to obtain the whole linear time-varying parameters dynamic mathematical model. The $2 \mathrm{MW}$ cage wind turbines were taken as example. The proposed model is validated by the study on the dynamic characteristics of cage wind turbines with wind speed variation.

\section{Mathematical Models of the Subsystems}

\subsection{Aerodynamic Mathematical Model}

Wind turbine converts the wind energy into mechanical energy and the amount of mechanical energy has the cubic relationship with the wind speed. The relationship can be represented by equation (1).

$$
P_{W T}=\frac{1}{2} \rho \pi R^{2} v^{3} C_{p}(\beta, \lambda)
$$

In Eq. (1), $P_{W T}$ is the mechanical power of the wind turbine; $\rho$ denotes the air density; $R$ represents the radius of wind wheel; $v$ is the weed speed; $\beta$ is the pitch angle; $\lambda$ is the blade top speed ratio; $C_{p}$ is the wind energy utilization efficiency of wind turbine; the relationship among $C_{p}, \beta$ and $\lambda$ can be expressed as equation (2).

$$
\left\{\begin{array}{c}
C_{p}(\beta, \lambda)=0.22\left(\frac{116}{\lambda_{i}}-0.4 \beta-5\right) e^{\frac{.22 .5}{\lambda_{i}}} \\
\frac{1}{\lambda_{i}}=\frac{1}{\lambda+0.08 \beta}-\frac{0.035}{\beta^{3}+1}
\end{array}\right.
$$

Fig. 1 describes the relationship among $C_{p}, \beta$ and $\lambda$. dynamic characteristics of cage wind turbines has been mainly studied in this paper considering the wind speed variation. In order to facilitate the analysis of the main problems, it is assumed that the cage wind turbine is running under the rated wind speed. Under this condition, the pitch angle is $0^{\circ}$, and then $C_{p}$ is only relevant to $\lambda$. 


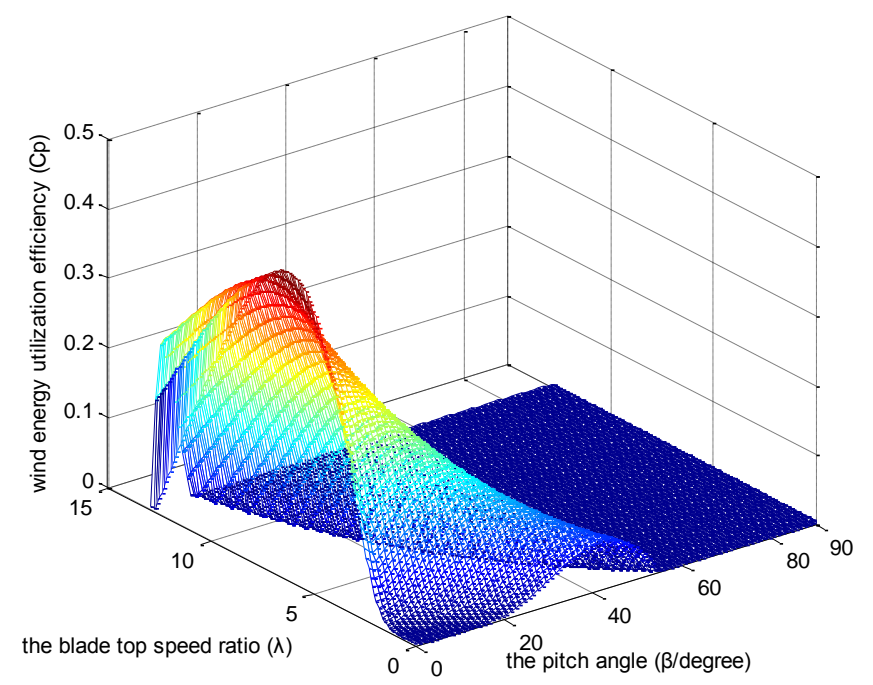

Figure 1 The Calculating Relations of $C_{\mathrm{p}}, \beta$ and $\lambda$

\subsection{Drive Train Mathematical Model}

Drive chain is a set of devices which connect the rotor shaft and the high-speed shaft of generator. Therefore, the rotor torque $\Gamma_{W T}$ and generator electromagnetic torque $\Gamma_{G}$ are taken as model inputs, and the speed of high-speed shaft $\Omega_{h}$ is the output. Assume that the influence of the drive chain's structure characteristics (such as vibration, gear type, backlash, etc.) on its performance can be neglected; therefore, the drive chain has constant mechanical transmission efficiency within the whole speed range.

According to the different research purpose, wind turbine generators' drive chain is usually divided into rigid drive chain and flexible drive chain. Rigid drive chain is that the whole wind turbine generators' drive chain can be expressed as a single rigid coupling accelerator, and in the flexible drive chain the elastic deformation of drive shaft would be considered. Flexible drive chain, compared with rigid drive chain, describes its energy transfer process of the wind turbine generators' drive chain much more objectively and specificly, but its differential equations are complex. The structure and differential equations of rigid drive chain are relatively simple so as to facilitate the establishment of wind turbines' overall dynamic mathematical model. Thus, in this paper the rigid drive chain has been chosen for the mathematical modeling.

The structure of rigid drive chain is shown in Fig.2. In that, $J_{W T}$ is the rotational inertia of rotor, $J_{l}$ is the rotational inertia of low speed shaft and $\Gamma_{W T}$ is wind rotor torque, $i$ and $\eta$ are the transmission ratio of gear box and the transmission efficiency. $J_{h}$ is the rotational inertia of high speed shaft, Error! Reference source not found. is the electromagnetic torque, $J_{g}$ is the rotational inertia of generator rotor.

Due to the role of accelerator, the electromagnetic torque Error! Reference source not found. is $i$ times less than the rotor torque $\Gamma_{W T}$, while the angular velocity $\Omega_{h}$ has increased $i$ times, namely Error! Reference source not found.=iError! Reference source not found.. Rigid drive chain model can be represented by equations (3) and (4).

$$
J_{h} \frac{d \Omega_{h}}{d t}=\frac{\eta}{i} \Gamma_{W T}\left(\Omega_{1}, v\right)-\Gamma_{G}\left(\Omega_{h}, c\right)
$$




$$
J_{l} \frac{d \Omega_{1}}{d t}=\Gamma_{W T}\left(\Omega_{l}, v\right)-\frac{i}{\eta} \Gamma_{G}\left(\Omega_{h}, c\right)
$$

In equations (3) and (4), $\Gamma_{W T}$ (Error! Reference source not found., v) selects the wind speed $v$ and low speed shaft's rotational speed Error! Reference source not found.as parameters. $\Gamma_{G}$ (Error! Reference source not found., $c$ ) selects Error! Reference source not found. and $c$ as parameters, $c$ stands for load variable, and it is a constant in the stable operation system. The calculation of $J_{h}$ and $J_{l}$ can be expressed by equations (5) and (6).

$$
\begin{aligned}
& J_{h}=\left(J_{1}+J_{w t}\right) \frac{\eta}{i^{2}}+J_{2}+J_{g} \\
& J_{l}=J_{1}+J_{w t}+\left(J_{2}+J_{g}\right) \frac{i^{2}}{\eta}
\end{aligned}
$$

In (5) and (6), Error! Reference source not found.andError! Reference source not found. are the inertia of overdrive gear.

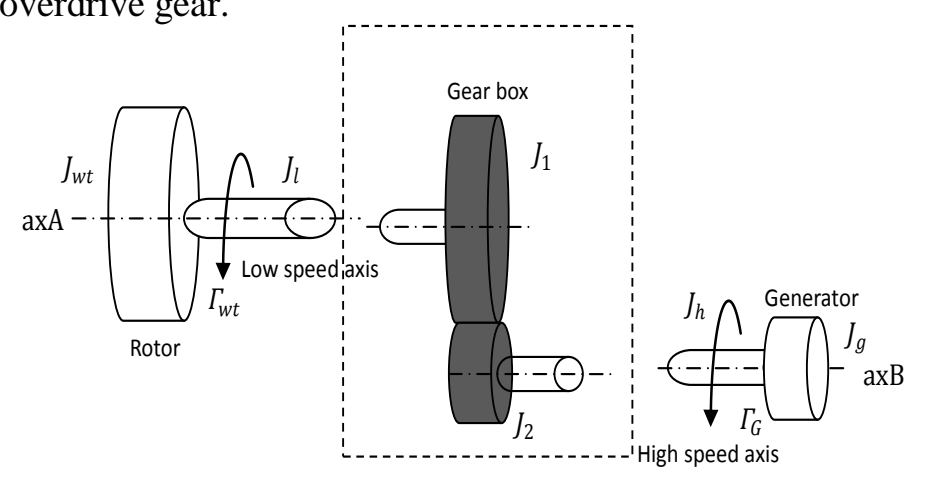

Figure 2 The Structure of Rigid Drive Train

\subsection{Generator Mathematical Model}

The electromagnetic torque equation of cage induction generator in $(\mathrm{d}, \mathrm{q})$ coordinate can be expressed by equation (7).

$$
\Gamma_{G}=\left(\frac{3}{2}\right) p L_{m}\left(i_{S q} i_{R d}-i_{R q} i_{S d}\right)
$$

In (7), $p$ is the number of pole pairs, $L_{m}$ is the mutual inductance between the stator and rotor, $i_{S d}, i_{S q}, i_{R d}, i_{R q}$ are the current component of the stator and rotor in $(d, q)$ coordinate, the dynamic equations of current component are shown in (8) [13-14].

$$
\left\{\begin{array}{l}
\frac{d i_{S d}}{d t}=\frac{U_{S d}}{L_{s}}-\frac{R_{s}}{L_{s}} i_{S d}-\frac{L_{m}}{L_{s}} \frac{d i_{R d}}{d t}+\omega_{s}\left(i_{s q}+\frac{L_{m}}{L_{s}} i_{R q}\right) \\
\frac{d i_{S q}}{d t}=\frac{U_{S q}}{L_{s}}-\frac{R_{s}}{L_{s}} i_{S q}-\frac{L_{m}}{L_{s}} \frac{d i_{R q}}{d t}-\omega_{s}\left(i_{s d}+\frac{L_{m}}{L_{s}} i_{R d}\right) \\
\frac{d i_{R d}}{d t}=\frac{U_{R d}}{L_{R}}-\frac{R_{R}}{L_{R}} i_{R d}-\frac{L_{m}}{L_{R}} \frac{d i_{S d}}{d t}+\left(\omega_{s}-\omega\right)\left(i_{R q}+\frac{L_{m}}{L_{R}} i_{s q}\right) \\
\frac{d i_{R q}}{d t}=\frac{U_{R q}}{L_{R}}-\frac{R_{R}}{L_{R}} i_{R q}-\frac{L_{m}}{L_{R}} \frac{d i_{S q}}{d t}+\left(\omega_{s}-\omega\right)\left(i_{R d}+\frac{L_{m}}{L_{R}} i_{S d}\right)
\end{array}\right.
$$


In (8), $\omega$ is the rotating frequency of rotor flux ( $\mathrm{rad} / \mathrm{s}), \omega=p$ Error! Reference source not found.; Error! Reference source not found. is the rotational angular velocity of generator's rotor, $\omega_{S}$ is the rotating frequency of stator flux $(\mathrm{rad} / \mathrm{s}), \omega_{S}=d \theta_{S} / d t ; \theta_{S}$ is the rotating angle of stator flux, $R_{S}$ and $R_{R}$ are the resistance of stator and rotor; $L_{S}$ and $L_{R}$ are the inductance of stator and rotor; $U_{S d}, U_{S q}, U_{R d}, U_{R q}$ are the voltage components of stator and rotor in $(d, q)$ coordinate. According to the structure of cage wind turbines It is known that $U_{R d}=U_{R q}=0$, so the current and voltage in the equation (8) can be expressed in vector form as equation (9).

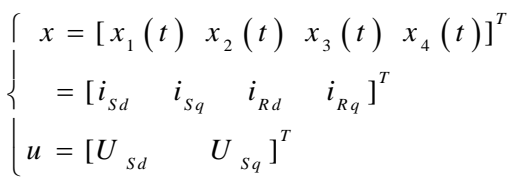

To take $x$ as state variable and $u$ as input variable, the state equations of cage wind turbines' generator can be expressed as 4-order linear state equations in equation (10).

$$
\left\{\begin{array}{l}
x=A\left(\Omega_{h}\right) x+B u \\
y=\Gamma_{G}=\frac{3 p L_{m}}{2}\left(x_{2} x_{3}-x_{1} x_{4}\right)
\end{array}\right.
$$

To make $\sigma=1-L_{m}{ }^{2} /\left(L_{S} \cdot L_{R}\right), \mathrm{A}$ and B can be expressed by the equations (11) and (12).

$$
A\left(\Omega_{h}\right)=\left\{\begin{array}{cccc}
-\frac{R_{s}}{\sigma L_{s}} & \omega_{s}+\frac{p \Omega_{h} L_{m}{ }^{2}}{\sigma L_{s} L_{R}} & \frac{L_{m} R_{R}}{\sigma L_{s} L_{R}} & \frac{p \Omega_{h} L_{m}}{\sigma L_{s}} \mid \\
-\left[\omega_{s}+\frac{p \Omega_{h} L_{m}{ }^{2}}{\sigma L_{s} L_{R}}\right] & -\frac{R_{s}}{\sigma L_{s}} & -\frac{p \Omega_{h} L_{m}}{\sigma L_{s}} & \frac{L_{m} R_{R}}{\sigma L_{s} L_{R}} \mid \\
\frac{L_{m} R_{R}}{\sigma L_{s} L_{R}} & -\frac{p \Omega_{h} L_{m}}{\sigma L_{R}} & -\frac{R_{R}}{\sigma L_{R}} \omega_{s} & -\frac{p \Omega_{h}}{\sigma} \mid \\
\frac{p \Omega_{h} L_{m}}{\sigma L_{R}} & \frac{L_{m} R_{R}}{\sigma L_{s} L_{R}} & \frac{p \Omega_{h}}{\sigma}-\omega_{s} & -\frac{R_{R}}{\sigma L_{R}}
\end{array}\right]
$$

In Eq. (11), the coefficient matrix $A$ is related to the angle velocity of high speed shaftError! Reference source not found., and Error! Reference source not found. is related to the wind speed $v$. Therefore, the coefficient matrix $A$ is a time-varying parameter matrix, which will change with the wind speed $v$.

\section{Overall Mathematical Model of Cage Wind Turbines System}

As mentioned before, the aerodynamic mathematical model, the drive chain mathematical model and the generator mathematical model of cage wind turbines have been proposed. How to integrate the above three separate sub-models into a whole dynamic mathematical model of the cage wind turbines will be studied as follow.

The calculation equation of wind wheel torque $\Gamma_{W T}$ (Error! Reference source not found.,v) is shown as equation (13).

$$
\Gamma_{w t}\left(\Omega_{l}, v\right)=\frac{P_{w t}}{\Omega_{l}}=0.5 \pi \rho v^{2} R^{3} C_{\Gamma}(\lambda)
$$

Where $C_{I}=C_{p} / \lambda, \lambda=R \cdot$ Error! Reference source not found. $/ v$. 
Equation (3) can be converted to equation (14).

$$
\frac{d \Omega_{h}}{d t}=\frac{\eta}{J_{h} i} \Gamma_{w t}\left(\Omega_{1}, v\right)-\frac{\Gamma_{G}\left(\Omega_{h}, c\right)}{J_{h}}
$$

$\Gamma_{W T}$ (Error! Reference source not found.,v) and $\Gamma_{G}$ (Error! Reference source not found.,v) in (14) can be replaced by (13) and (7) as shown in equation (15).

$$
\frac{d \Omega_{h}}{d t}=0.5 \frac{\eta}{J_{h} i} \pi \rho v^{2} R^{3} C_{\Gamma}(\lambda)-\frac{\left(\frac{3}{2}\right) p L_{m}\left(i_{s_{q}} i_{R d}-i_{R q} i_{s d}\right)}{J_{h}}
$$

The whole state equation of the cage wind turbines can be obtained combining the equations (15) and (8) which can be expressed as equation (16).

$$
\left\{\begin{array}{l}
\frac{d i_{s d}}{d t}=\frac{U_{s d}}{L_{s}}-\frac{R_{s}}{L_{s}} i_{s d}-\frac{L_{m}}{L_{s}} \frac{d i_{R d}}{d t}+\omega_{s}\left(i_{s q}+\frac{L_{m}}{L_{s}} i_{R q}\right) \\
\frac{d i_{s q}}{d t}=\frac{U_{S q}}{L_{s}}-\frac{R_{s}}{L_{s}} i_{s q}-\frac{L_{m}}{L_{s}} \frac{d i_{R q}}{d t}-\omega_{s}\left(i_{s d}+\frac{L_{m}}{L_{s}} i_{R d}\right) \\
\frac{d i_{R d}}{d t}=\frac{U_{R d}}{L_{R}}-\frac{R_{R}}{L_{R}} i_{R d}-\frac{L_{m}}{L_{R}} \frac{d i_{s d}}{d t}+\left(\omega_{s}-\omega\right)\left(i_{R q}+\frac{L_{m}}{L_{R}} i_{s q}\right) \\
\frac{d i_{R q}}{d t}=\frac{U_{R q}}{L_{R}}-\frac{R_{R}}{L_{R}} i_{R q}-\frac{L_{m}}{L_{R}} \frac{d i_{s q}}{d t}+\left(\omega_{s}-\omega\right)\left(i_{R d}+\frac{L_{m}}{L_{R}} i_{S d}\right) \\
\frac{d \Omega_{h}}{d t}=0.5 \frac{\eta}{J_{h} i} \pi \rho v^{2} R^{3} C_{\Gamma}(\lambda)-\frac{\left(\frac{3}{2}\right) p L_{m}\left(i_{s q} i_{R d}-i_{R q} i_{s_{S d}}\right)}{J_{h}}
\end{array}\right.
$$

As shown in eq. (16), the first expression at the right of the equal sign in the fifth differential equations is the nonlinear expression of the input variable $v$, and the second expression is also the nonlinear expression of the state variables $i_{S d}, i_{S q}, i_{R d}, i_{R q}$. The before 4 equations in eq. (16) can be expressed unitarily as $x=A$ (Error! Reference source not found.) $x+B u$. Because the coefficient matrix $A$ is a time-varying parameter matrix, therefore, the overall state equation of cage wind turbines has the nonlinear and time-varying characteristics. In order to take the advantage of the knowledge of the linear state space to carry out research, the whole model needs to be linearized.

\section{System Mathematical Model Linearization}

Since the nonlinear characteristic of the state equations of the wind turbine, it is not conducive to the study of dynamic characteristics; and the state equation is linearized in this section as follow.

For the cage wind turbines, system input variables should include not only the wind speed $v$, but also include the stator voltage; while the state variables of the system contains the stator current $\left(i_{S d}, i_{S q}\right)$, rotor current $\left(i_{R d}, i_{R q}\right)$, and also the high speed shaft angular velocity Error! Reference source not found.. Therefore, the overall system state variables and input variables are given in the eq. (17).

$$
\text { Error! Reference source not found. } \begin{cases}x=\left[\begin{array}{lllll}
x_{1} & x_{2} & x_{3} & x_{4} & x_{5}
\end{array}\right]^{T} & \\
=\left[\begin{array}{lllll}
i_{s d} & i_{s q} & i_{R d} & i_{R q} & \Omega_{h}
\end{array}\right] & \text { Error! } \\
u=\left[\begin{array}{llll}
U_{s d} & U_{s q} & v
\end{array}\right]^{T} & \end{cases}
$$

Reference source not found. 
From the characteristic of wind turbine, it is known that the rotor torque $\Gamma_{W T}$ (Error! Reference source not found.,v) and low speed shaft angular velocity Error! Reference source not found. were relative to the wind speed $v$ which is shown in Fig. 3. In this diagram, electromagnetic torque operation line is located on the right side of the wind wheel torque curve. When the wind turbine operates at the stable operating point OP, as shown in the system dynamic equation (16), the current state of the generator can be described by six dimensional vectors $\left(\overline{i_{s d}} \overline{i_{s q}} \overline{i_{R d}} \overline{i_{R q}} \overline{\Omega_{h}} \bar{v}\right)=(\bar{x}, \bar{v})$.

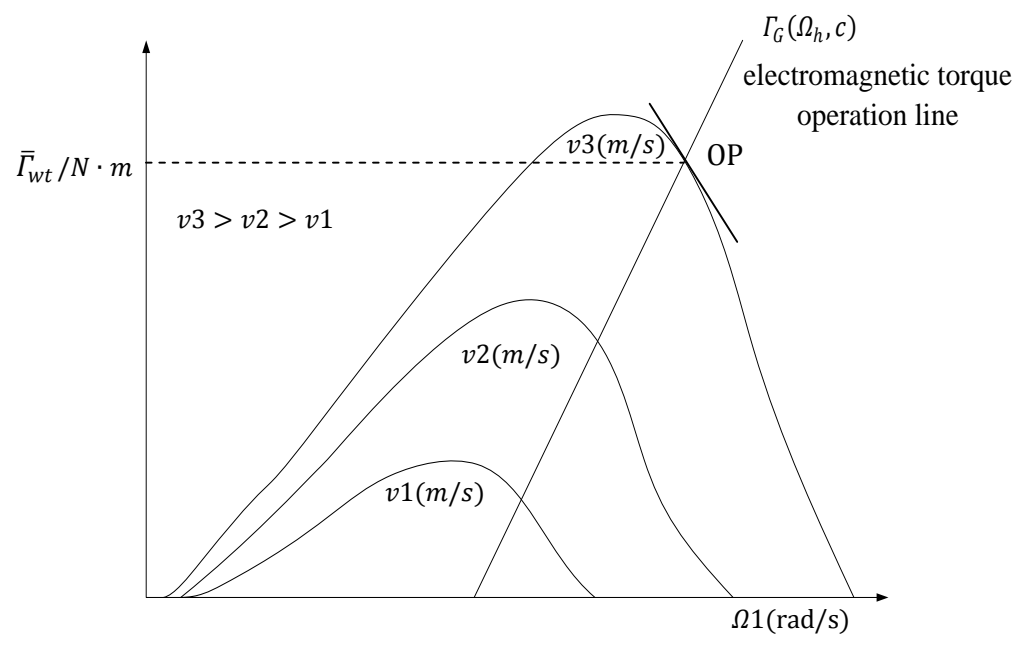

Figure 3 The Calculating Relations of Error! Reference source not found.,Error! Reference source not found. and Error! Reference source not found.

When the running state of the cage wind turbines has a very small change near the stable operation point $\mathrm{OP}$, the state variables and input variables would also have small changes, the value of this change as shown in equation (18).

$$
\left\{\begin{array}{l}
\Delta x=\left[\begin{array}{lllll}
\Delta i_{s d} & \Delta i_{s q} & \Delta i_{R d} & \Delta i_{R q} & \Delta \Omega_{h}
\end{array}\right] \\
\Delta u=\left[\begin{array}{lll}
\Delta U_{s d} & \Delta U_{s q} & \Delta v
\end{array}\right]^{T}
\end{array}\right.
$$

Based on the theory of infinitesimal calculus, a tiny variation of the system could be calculated by equation (19).

$$
\nabla y=\frac{\partial f}{\partial z} \nabla z
$$

In eq. (19), $\nabla y$ is the changes of the system output variable, $\alpha f / \alpha z$ is the derivation of the system equation, and $\nabla$ is the changes of the system input variables.

When the wind turbine is running at stable operation point $\mathrm{OP}$, according to the derivation rules of the equation (19), the derivation value of the first equation in (10) could be described as (20) and (21). 


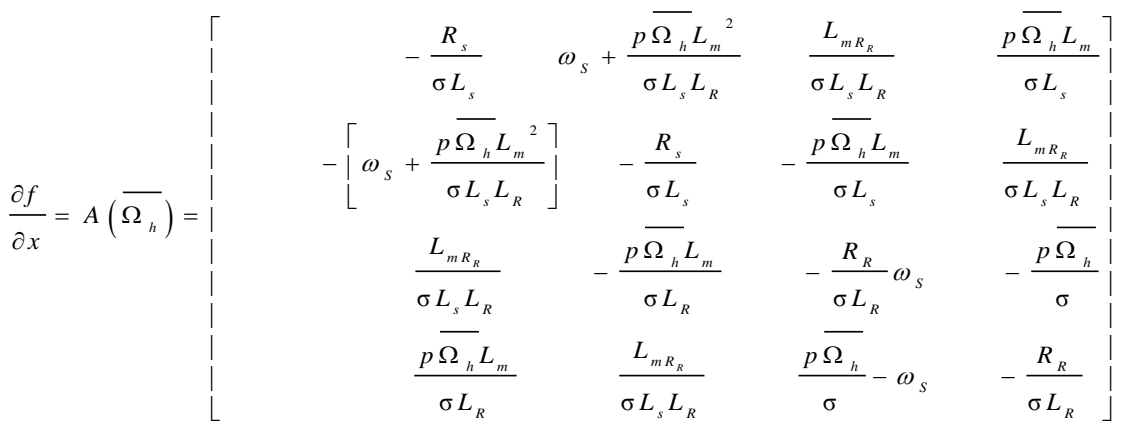

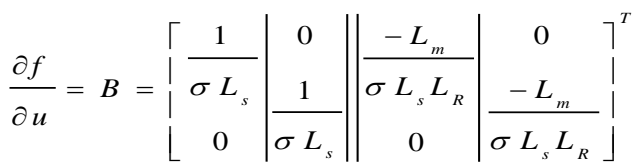

Take derivative of $\Gamma_{W T}$ (Error! Reference source not found.,v) in eq. (13) with respect to Error! Reference source not found. and $v$ respectively when the wind turbines were running at stable operation point OP, the derivation value can be expressed as (22).

$$
\Delta \Gamma_{w t}=\frac{\gamma \pi \rho R^{3}}{2} C_{\Gamma}(\bar{\lambda}) \cdot \frac{\bar{v}^{-2}}{\overline{\Omega_{l}}} \cdot \Delta \Omega_{l}+\frac{(2-\gamma) \pi \rho R^{3}}{2} C_{\Gamma}(\bar{\lambda}) \cdot \bar{v} \cdot \Delta v
$$

In (22), $\gamma=\gamma(\bar{\lambda})=C_{p}^{\prime}(\bar{\lambda}) \cdot \bar{\lambda} / C_{p}(\bar{\lambda})-1$.

The equation (3) can be converted to the equation (23).

$$
i J_{h} \frac{d \Omega_{h}}{d t}=\eta \Gamma_{w t}\left(\Omega_{l}, v\right)-i \Gamma_{G}\left(\Omega_{h}, c\right)=\Delta \Gamma_{w t}
$$

From rigid drive chain it is known that $\overline{\Omega_{h}}=i \overline{\Omega_{1}}$, and equation (23) can be changed to equation (24).

$$
\frac{d \Omega_{h}}{d t}=\frac{\gamma \pi \rho R^{3}}{2} C_{\Gamma}(\bar{\lambda}) g \frac{\bar{v}^{2}}{\overline{\Omega_{h}}} g \Delta \Omega_{h}+\frac{(2-\gamma) \pi \rho R^{3}}{2} C_{\Gamma}(\bar{\lambda}) g \bar{v} g \Delta v
$$

So far, the derivative values of all the equations in equation (16) operating at the point OP have been obtained. The system dynamic changes at point OP can be represented by equation (25).

$$
x=A(\bar{x}, \bar{v}) \cdot x+B\left(\overline{\Omega_{h}}, \bar{v}\right) \cdot u
$$

In (25), $x=\left[\begin{array}{lllll}\Delta i_{s d} & \Delta i_{s q} & \Delta i_{R d} & \Delta i_{R q} & \Delta \Omega_{h}\end{array}\right], u=\left[\begin{array}{llll}\Delta U_{s d} & \Delta U_{s q} & \Delta v\end{array}\right]^{T}$, the expression of $A(\bar{x}, \bar{v})$ and $B\left(\overline{\Omega_{h}}, \bar{v}\right)$ could be shown as the equation (26) and (27) respectively. 


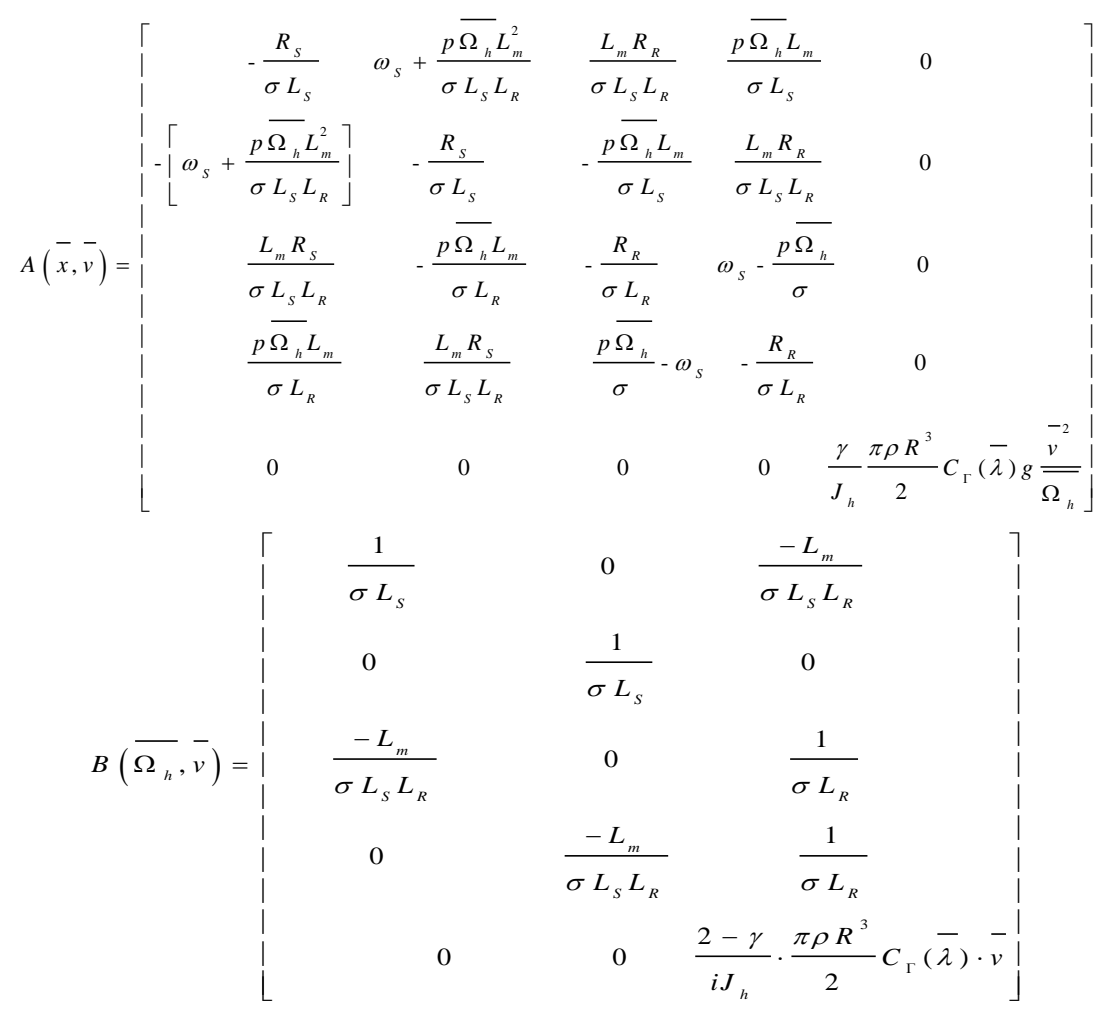

\section{Simulation Analyses}

To take a cage wind turbine as example, the parameters of this wind turbine for stator resistance $R s=0.0011 \Omega$, stator inductance $L s=0.0031 \mathrm{H}$, rotor resistance $R r=0.0013 \Omega$, rotor inductance $L r=0.0031 \mathrm{H}$, the mutual inductance of stator and rotor $L m=0.0030 H$, and the number of pole pairs $p=2$, the outlet voltage of generator is $690 \mathrm{~V}$, system frequency $50 \mathrm{~Hz}$, the radius of the wind wheel $R=45 \mathrm{~m}$.

Figure 4 is the change process of the eigenvalue of the cage wind turbine drive chain along with the wind speed variation. As shown in figure 4 , the coordinate values of the drive chain eigenvalue are negative real numbers without any of the imaginary axis part; it corresponds to the choice of first-order rigid drive chain model in this case. In figure 4 , the direction of the arrow represents the direction of the wind speed increase, and wind speed changes from 4 to $16 \mathrm{~m} / \mathrm{s}$. It is can be known in figure 4 that the eigenvalue of cage wind turbine drive chain decreases when wind speed increases from 4 to $8 \mathrm{~m} / \mathrm{s}$, on the contrary, the eigenvalue increases when wind speed increases from 8 to $16 \mathrm{~m} / \mathrm{s}$. So, it is can be concluded that the dynamic response process of drive chain is enhanced firstly and weakened later along with wind speed changes from 4 to $16 \mathrm{~m} / \mathrm{s}$. 


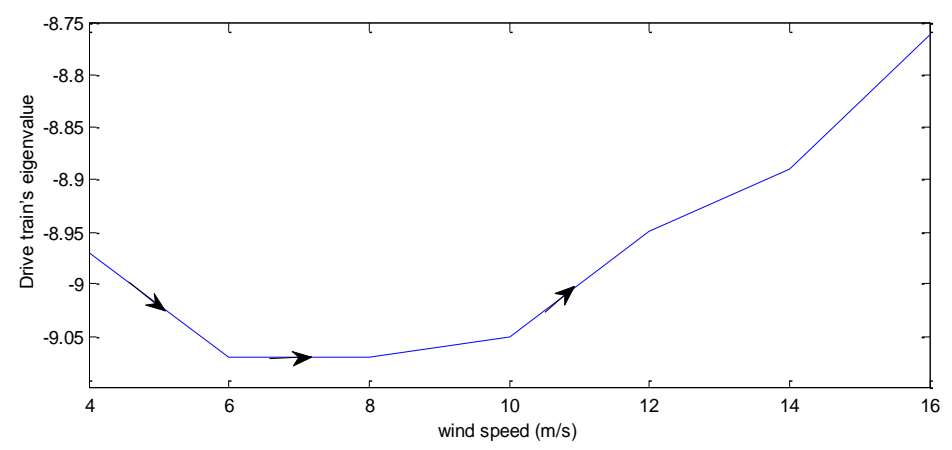

Figure 4 Drive Train's Eigenvalue

Figure 5 shows the real part of the eigenvalue of cage wind turbine rotor. From the change process of the rotor eigenvalue's real part, it is known that the rotor eigenvalue's real part increases when wind speed changes from 4 to $8 \mathrm{~m} / \mathrm{s}$, on the contrary, the rotor eigenvalue's real part decreases when wind speed changes from 8 to $16 \mathrm{~m} / \mathrm{s}$. So, it is can be concluded that the dynamic response process of cage wind turbine rotor is weakened firstly and later enhanced along with wind speed changes from 4 to $16 \mathrm{~m} / \mathrm{s}$.

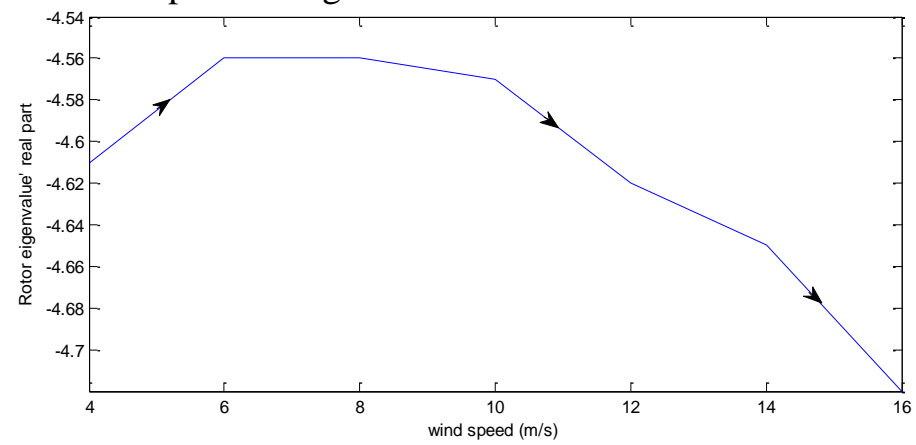

Figure 5 Rotor Eigenvalue' Real Part

Figure 6 shows the imaginary part of the eigenvalue of cage wind turbine rotor. From the change process of the rotor eigenvalue's imaginary part, it is known that the rotor eigenvalue's imaginary part increases when wind speed changes from 4 to $10 \mathrm{~m} / \mathrm{s}$, on the contrary, the rotor eigenvalue's imaginary part decreases when wind speed changes from 10 to $16 \mathrm{~m} / \mathrm{s}$. So, it is can be concluded that the dynamic oscillation characteristics of cage wind turbine rotor is weakened firstly and later enhanced along with wind speed changes from 4 to $16 \mathrm{~m} / \mathrm{s}$.

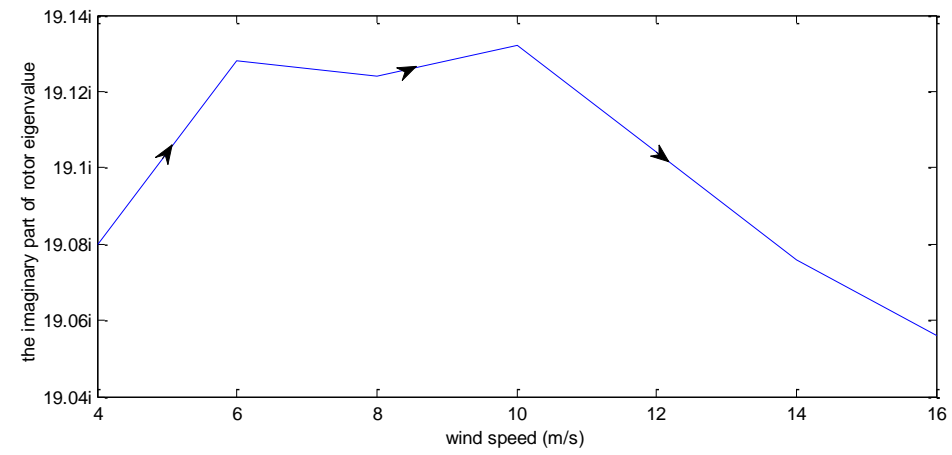

Figure 6 Rotor Eigenvalue' Imaginary Part 
According to cage wind turbine knowledge and parameter values described above, the simulation model of grid connected cage wind turbines was constructed; the overall architecture of the simulation model is shown in Figure 7.

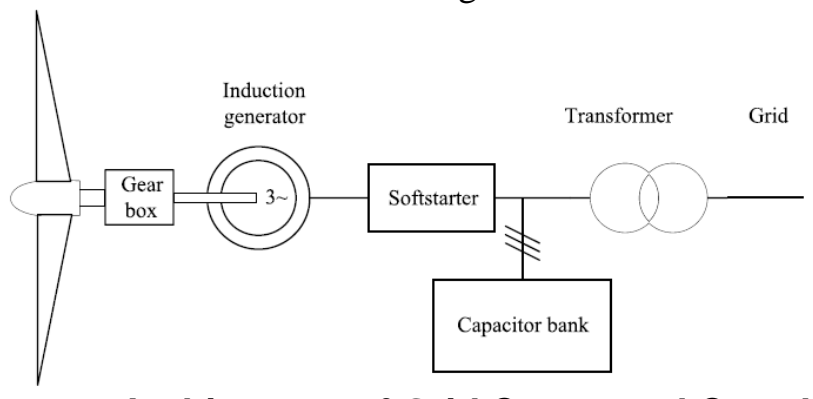

\section{Figure 7 The System Architecture of Grid Connected Cage Wind Turbines}

Figure 8 is the dynamic response of the drive chain which is obtained from the simulation model in figure 7 , the dotted line represents the dynamic response of the drive chain when wind speed changes from 4 to $6 \mathrm{~m} / \mathrm{s}$ at the first 5 seconds, the solid line represents the dynamic response of the drive chain when wind speed changes from 6 to $8 \mathrm{~m} / \mathrm{s}$ at the first 5 seconds. It is can be known from figure 8 that the solid line and the dotted line reach the peak point at the same time, but the slope of the solid line is larger than the dotted line, therefore, it indicates that the dynamic response speed of drive chain when wind speed is $6 \mathrm{~m} / \mathrm{s}$ is larger than wind speed at $4 \mathrm{~m} / \mathrm{s}$, the simulation results is consistent with the results of the theoretical analysis, this proves the correctness of the above theoretical part.

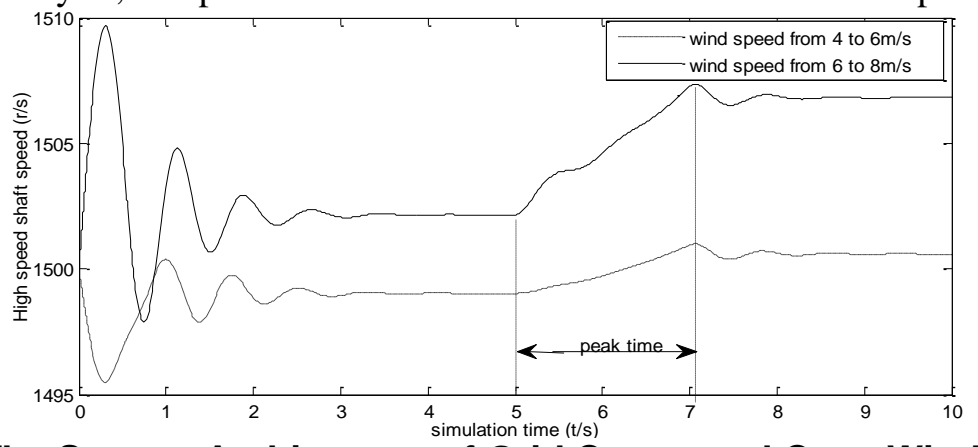

Figure 8 The System Architecture of Grid Connected Cage Wind Turbines

Figure 9 is the dynamic response of the $d$ axis components of the rotor current which is obtained from the simulation model in figure 7. The dotted line represents the dynamic response of the $d$ axis components of the rotor current when wind speed changes from 4 to 6 $\mathrm{m} / \mathrm{s}$ at the first 5 seconds, the solid line represents the dynamic response of the $\mathrm{d}$ axis components of the rotor current when wind speed changes from 7 to $9 \mathrm{~m} / \mathrm{s}$ at the first 5 seconds. It is can be known from figure 9 that the solid line and the dotted line reach the peak point at the same time too, but the slope of the solid line is larger than the dotted line, therefore, it indicates that the dynamic response speed of the $\mathrm{d}$ axis components of the rotor current when wind speed is $7 \mathrm{~m} / \mathrm{s}$ is larger than wind speed at $4 \mathrm{~m} / \mathrm{s}$, the simulation results is consistent with the results of the theoretical analysis, the correctness of the theoretical part above is proved too. 


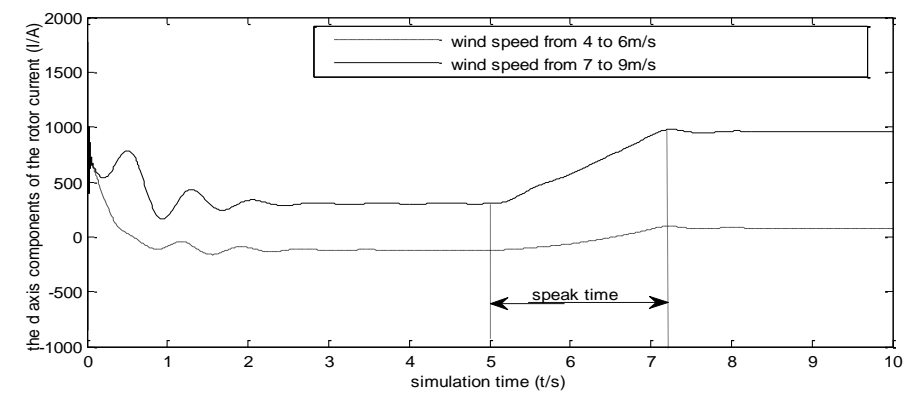

\section{Figure 9 The Dynamic Response of the $\mathrm{d}$ axis Components of the Rotor Current}

The change process of dynamic characteristics of the whole cage wind turbine was studied when wind speed changed, the rule that dynamic characteristics change with wind speed change of the drive train and rotor is studied detailed, and the simulation model based on the results was set up, and the correctness of the contents of this article was proved too.

\section{Conclusion}

This paper based on the energy conversion principle of cage wind turbine, established a cage wind turbine overall nonlinear time-varying parameters of dynamic mathematical model, and the nonlinear time-varying parameters dynamic mathematical model is linearized.

Based on getting a general linear time-varying parameters dynamic mathematical model, the 2MW cage wind turbines wind turbine was taken as example. When the wind speed changes from 4 to $16 \mathrm{~m} / \mathrm{s}$, the simulation results show that:

1) The dynamic response process of drive chain of cage wind turbine is enhanced firstly and weakened later along with wind speed changes from 4 to $16 \mathrm{~m} / \mathrm{s}$.

2) Cage wind turbine rotor's dynamic response process is weakened firstly and later enhanced along with wind speed changes from 4 to $16 \mathrm{~m} / \mathrm{s}$.

3) The dynamic oscillation characteristics of cage wind turbine rotor is weakened firstly and later enhanced along with wind speed changes from 4 to $16 \mathrm{~m} / \mathrm{s}$.

\section{References}

[1] L. Jing, W. Weisheng and S. Jiahua, "Simplified Dynamic Model of Doubly-Fed Induction Generator and Its Application in Wind Power", Electric Power Automation Equipment, vol. 25, (2005) January, pp. 5862.

[2] A. Feijoo, J. Cidras and C. Carrillo, "A Third Order Model for the Doubly-Fed Induction Machine", Electric Power Systems Research, vol. 56, (2000) November, pp. 121-127.

[3] C. Yan, O. Gaofei, W. Haibing and Y. Zhiquan, "Dynamic Model Analysis for Variable Speed Wind Turbine", Acta Energiae Solaris Sinica, vol. 25, (2004) June, pp. 724-727.

[4] Y. Guangxin, C. Qin, L. Xingang and Z. Wei, "Dynamic Stability Simulation of Double-Fed Wind Generator Connected into Power Grid", Power System Technology, vol. 31, (2007) December, pp. 53-65.

[5] J. B. Ekanayake, L. Holdsworth, X. Wu and N. Jenkins, "Dynamic Modeling of Doubly Fed Induction Generator Wind Turbines”, IEEE Transactions on Power Systems, vol. 18, (2003) February, pp. 803-809.

[6] Y. Min, Y. Minchen and J. Chuanwen, et al., "Study on power system reliability and reserve optimization with wind power integration", Power System Protection and Control, vol. 40, (2012) June, pp. 110-114.

[7] W. Lifang, Z. Rui and Q. Jian, et al., "An on-line early warning system for voltage stability in regional power grid considering wind power and electrified railway load", Power System Protection and Control, vol. 40, (2012) May, pp. 75-81.

[8] B. Nengsheng, X. Junping, N. Weidou and Y. Zhiquan, "Dynamic Characteristics of Large-Scale Stall Wind Turbine System", Acta Energiae Solaris Sinica, vol. 28, (2007) November, pp. 1330-1333.

[9] L. Dongdong and C. Chen, "A Study on Dynamic Model of Wind Turbine Generator Sets", Proceedings of the CSEE, vol. 25, (2005), pp. 115-119. 
[10] Y. Ming, L. Gengyin, Z. Ming and Z. Chengyong. "Analysis and Comparison of Dynamic Models for the Doubly-Fed Induction Generator Wind Turbine", Automation of Electric Power Systems, vol. 30, (2006) July, pp. 22-27.

[11] M. Rahimi and M. Parniani, "Dynamic Behavior Analysis of Doubly-Fed Induction Generator Wind Turbines-The Influence of Rotor and Speed Controller Parameters”, Electrical Power and Energy Systems, vol. 32, (2010) June, pp. 464-477.

[12] M. Rahimi and M. Parniani, "Dynamic Behavior and Transient Stability Analysis of Fixed Speed Wind Turbines", Renewable Energy, vol. 34, (2009) December, pp. 2613-2624.

[13] N. D. Caliao, "Dynamic Modeling and Control of Fully Rated Converter Wind Turbines", Renewable Energy, vol. 36, (2011) August, pp. 2287-2297.

[14] A. H. M. A. Rahim, M. A. Alam and M. F. Kandlawala, "Dynamic Performance Improvement of an Isolated Wind Turbine Induction Generator", Computers and Electrical Engineering, vol. 35, (2009) July, pp. 594-607.

[15] X. Hui, L. Yong and L. Hui-jin, "Comparison of two calculation methods of flicker caused by wind power”, Power System Protection and Control, vol. 39, (2011) October, pp. 66-77.

[16] L. Xiong, L. Gangqiang, C. Yan, Y. Zhiquan and T. Peng, "Dynamic Response Analysis of the Tubular Tower of Horizontal Axis Wind Turbines", Acta Energiae Solaris Sinica, vol. 31, (2010) April, pp. 412416.

[17] C. Yan, T. Peng, L. Xiong, L. Zhen and Y. Zhiquan, "Research on Static and Dynamic Characteristics of Cone-Shaped Tower of HAWTs", Acta Energiae Solaris Sinica, vol. 31, (2010) October, pp. 1359-1365.

[18] S. Adhikari and S. Bhattacharya, "Dynamic Analysis of Wind Turbine Towers on Flexible Foundations", Shock and Vibration, vol. 19, (2012) January, pp. 37-56.

[19] A. Quilligan, A. O. Connor and V. Pakrashi, "Fragility analysis of steel and concrete wind turbine towers", Engineering Structures, vol. 36, (2011) March, pp. 270-278.

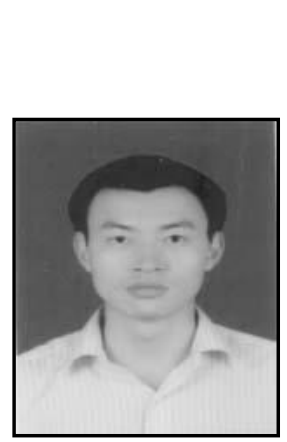

\section{Author}

Gu Bo received the Master degree in North China University of Water Resources and Electric Power in 2006. Currently, he is a lecturer at North China University of Water Resource and Electric power. His interests are in new energy generation technologies. 